\title{
Desertification risk mapping of the Zayandeh Rood Basin in Iran
}

\author{
M Marani Barzani* and O S Khairulmaini \\ Department of Geography, University of Malaya, Kuala Lumpur, Malaysia. \\ *Corresponding author.e-mail: marani82@yahoo.com, khairulo@um.edu.my
}

This paper presents a classified desertification hazard map of Zayandeh Rood Basin (Z.R.B) in Iran. There are potential climatic factors, the geographical location and human activities for developing desertification. The present study is based on the preview models and main factors of desertification in the study area. The classification method is based on such main parameters as the characteristic of soil, management and climate. Each parameter includes a sub-indicator with a weighing of between one and two based on the MEDALUS model. DEM, LANDSAT images (ETM+), statistical data and vector map are used as the dataset for classifying the desertification map. The sum of score parameters was estimated by using a weighted average. In this study, Arc GIS 9.3 was used to analyze the vector and raster layer maps as well as a recognition survey of the study area using satellite images. In Z.R.B, the most important factors of desertification hazard are the geographical location of the area, salinization area, elevation, slope, and human activities. Thanks to the classification hazard map, the highest class is located on salinization, low vegetation, high wind erosion, low slope and elevation. Low-class area of the hazard map belongs to the largest part of the basin. An important factor of desertification in the area can be the geographical location of the basin located near the desert area. Using the raster data and GIS software are beneficial for the classification hazard map, especially for large areas.

\section{Introduction}

Desertification refers to the process of land degradation which is the result of various factors in arid, semi-arid and dry sub-humid areas. Desertification is the process that affects such ecosystems as plants, soil and human activities (Alavipanah and Zehtabian 2001). The livelihoods of over 1.2 billion people inhabiting the dry land areas in 110 countries are currently threatened by drought and desertification (Gurung 2010). The characteristics of climate factors, lack of potential for vegetation in desert areas, growing human population and land use are important factors for developing desertification.

The geographical location of Iran shows that about $80 \%$ of the total area is located in an arid or semi-arid zone (Aminmansour 2006). As a result of the following factors, land degradation and desertification have accelerated in Iran during the recent decades: first, the population has doubled over the last 25 years (since 1979); second, increased agricultural and pastoral products have forced people to use land extensively or convert forest and rangelands to cultivated land; third, overuse of wood and plants as fuel for household cooking and heating, and use of natural regulations tend to denude the soil and intensify the desertification (Aminmansour 2006). Most of the factors affecting the desertification process in Iran are climatic such as fluctuations, drought, runoff, flood, water erosion and aridity, although mismanagement and land use alternations accelerate the desertification process and intensify the desertification.

Keywords. Desertification; classified desertification hazard map; Zayandeh Rood Basin. 
Qualitative and quantitative factors of desertification hazard can be used to assess the desertification hazard. One of the important measurable methods for preventing the desertification hazard is to identify the sensitive areas, which is made possible by using a classification hazard map. Classified hazard maps can be used to identify critical and prone areas that are beneficial to hazard management. A variety of methods such as the following have been used by researcher for assessing desertification.

In the early 1990s, FAO and UNEP dry lands in some Asian countries, the process factors were climatic quality and human activities (Ekhtesasi and Mohajeri 1995). Additionally, FAO and UNEP (1984) introduced a semi-quantitative method for desertification mapping based on the soil indicators and classified the desertification aspects, the potential and inherent risk as well as the rate and total risk. The desertification intensity has been subdivided on a scale of four divisions: slight to very severe (Sepehr 2007).

In the ESAS project referred to as MEDALUS, four major criteria involving soil, vegetation, management and climate have been investigated using the main indicators for each major criterion. The geometric mean has been used for quality mapping. Landform and geology characteristics were excluded from the assessment.

A geometric algorithm was used to combine the map for layers. Ladisa et al. (2002), Sepehr (2007) in Iran and Afif et al. (2010) in Egypt used the MEDALUS method to identify the sensitive areas in their case studies. Ekhtesasi and Mohajeri (1995) introduced the ICD (Iranian classification of desertification) method for assessment of desertification in Iran. ICD is rooted in identifying the different types of land use and vegetation. According to Ahmadi et al. (2006), using ICD method, climate, geomorphology, soil, geology and management were proposed.

The Greek National Committee of Combat against Desertification, Athens University (2001), produced a desertification map based on the GIS environment model developed on the overlapping layers. The desertification factors used in the method are climate, physiography, geology, soil hydrology and human effects (Greek National Committee for combating desertification 2001). Desertification occurs only in arid, semi-arid and sub-humid areas. The hyper-arid areas are natural deserts or environmental deserts with almost 1 billion hectares in the world. These are natural deserts.

Application of remote-sensing technologies in mapping of degraded lands has shown a great promise for enhanced speed, accuracy and costeffectiveness (Dwivedi and Sreenivas 1998). In the past 30 years, remote sensing has become a major technology in monitoring land desertification and reflecting desertification of land cover. A number of studies have been done using remote sensing (land sat) PAN (Hansen 1985; Graetz et al. 1988; Gosh 1993; Jing-hu and Tian-yu 2010) to extract and analyze desertification by LANDSAT images.

Desertification is a phenomenon occurring in the Zayandeh Rood Basin (Z.R.B.) in Iran. There are some reasons for desert and desertification of the area such as dry land, climatic qualities such as high temperature, high wind speed, high evaporation, low rainfall, closeness to the desert (in the centre of Iran), wind erosion and human activities. The eastern part of Z.R.B. is the location for desertification area; however, desertification also occurs in north and east of the area.

This paper attempts to develop a model for hazard classification map of Z.R.B. based on the situation of the study area using the pervious specific factors of desertification. The parameters include climate quality, wind and water erosion, lithology, soil parents, topography, geomorphology and management (figure 3).

\section{Study area}

The Z.R.B. is a hydrological basin in Iran. The study area is located northeast of the Z.R.B. in the central part of Iran with geographical coordinates of longitude $52^{\circ} 1^{\prime}-52^{\circ} 7^{\prime} \mathrm{N}$ and a latitude $32^{\circ} 36^{\prime}-32^{\circ} 40^{\prime} \mathrm{N}$ (figure 1 ). The maximum precipitation of the basin occurs during winter in January and February and the minimum in summer in July and August. The average annual precipitation is $105.84 \mathrm{~mm}$ and the average annual temperature is over $14.9^{\circ} \mathrm{C}$. The average evaporation is 2219.3. Wind erosion in the area shows an orientation of powerful winds blowing from west to southeast with an average wind speed of $3.5 \mathrm{~m} / \mathrm{s}$ (Khodagholi 2006). The most important factors in developing desertification in the study area are geographical location, non-normative exploitation of the surface mineral of gypsum mines, nonnormative exploitation of lands, reduced entrance runoff from upstream regions, sharp drop in groundwater level, winds and storms laden with chalk, dust and suspended particles, low precipitation and high evaporation.

\section{Materials and methodology}

\subsection{Materials}

The methodology was divided into five phases:

\subsubsection{Parameters selection}

The desertification hazard map is based on geographical parameters of Z.R.B. such as lithology, 


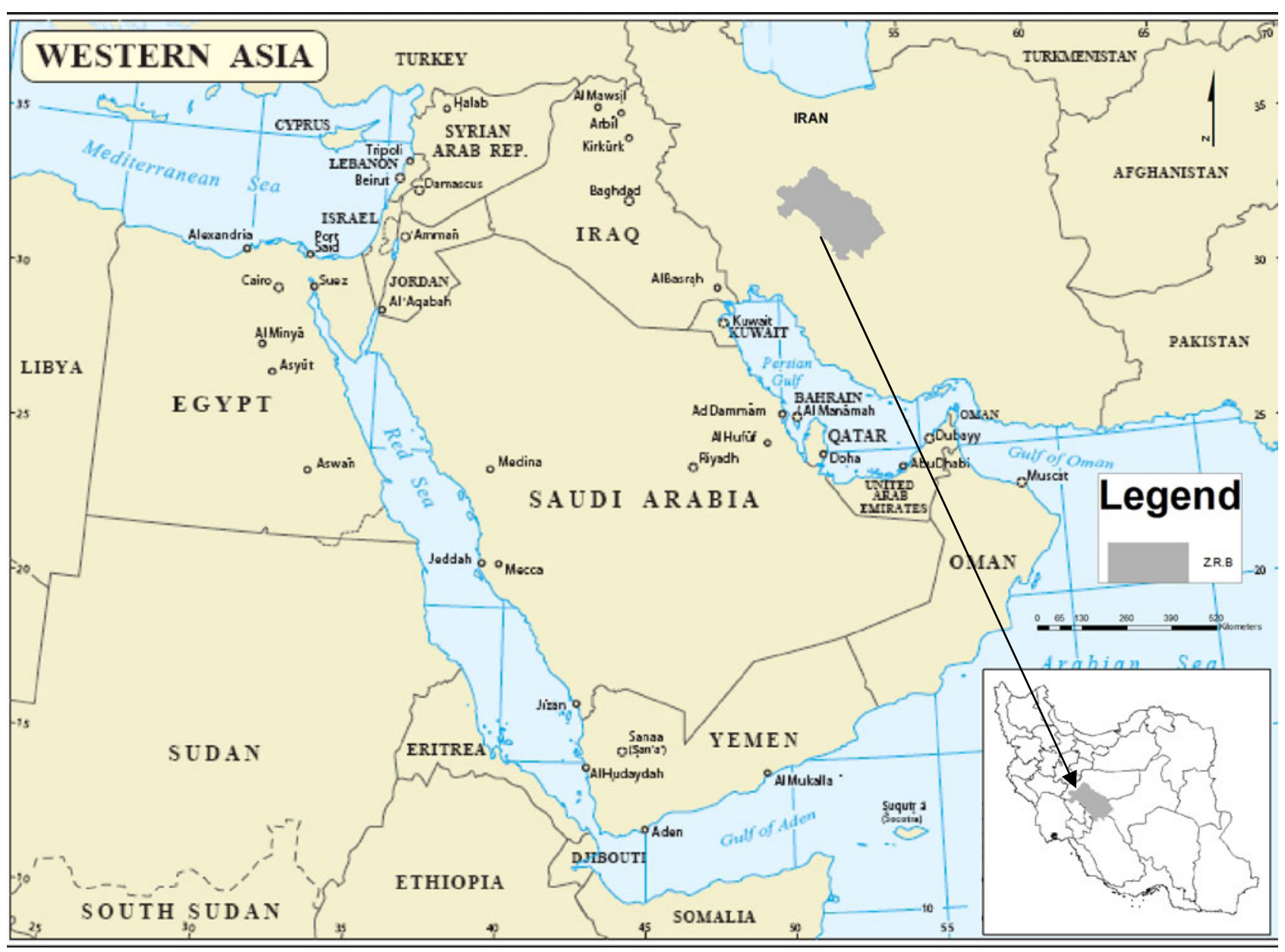

Figure 1. Geographical location of Z.R.B in Iran.

geomorphologic faces, climatic quality, topography, soil characteristics and management.

\subsubsection{Data source}

In this study, the datasets include the data for raster, vector, and statistics.

\subsubsection{Vector data}

Lithology map, land use, topography, the maps for land use and soil. The vector map was prepared by the Natural Resources Organization and classified based on the purpose in GIS environment and the topography map of 1:50,000 within the study area.

\subsubsection{Raster data}

The LANDSAT images ETM+ was taken to identify classification of the land use, distance of the desert area, salinization area and to check desertification classes. Figure 2 shows the ETM+ images of the study area. In this research, LANDSAT images ETM+ 2002 and ETM+ spectral band were used.
High quality images were selected in order to identify the land cover of the area with a high potential. In this study, the data formats were based on B.S.Q or continued band format and all the images converted the band in ER-Mapper environment. In this study ILWIS, ER-Mapper and Arc view were used for processing and analyzing purposes. The work done in the study area was filed for geometric corrections. In the following section, the image-processing technique will be explained.

Geometric correction of ETM images: The bands of LANDSAT images ETM+ were input to the ER-MAPPER environment software and their formats were converted and geometric corrections were made using a 50-point field work and topographical map with a 1:50,000 scale and GPS control in $0 / 5 \mathrm{~m}$ in pixels. In order to convert the panchromatic band with multi-spectral bands, it was necessary to correct the panchromatic band and then the other bands based on it.

Examinations of spectral curves band and composite colours: A profile was made to examine the 


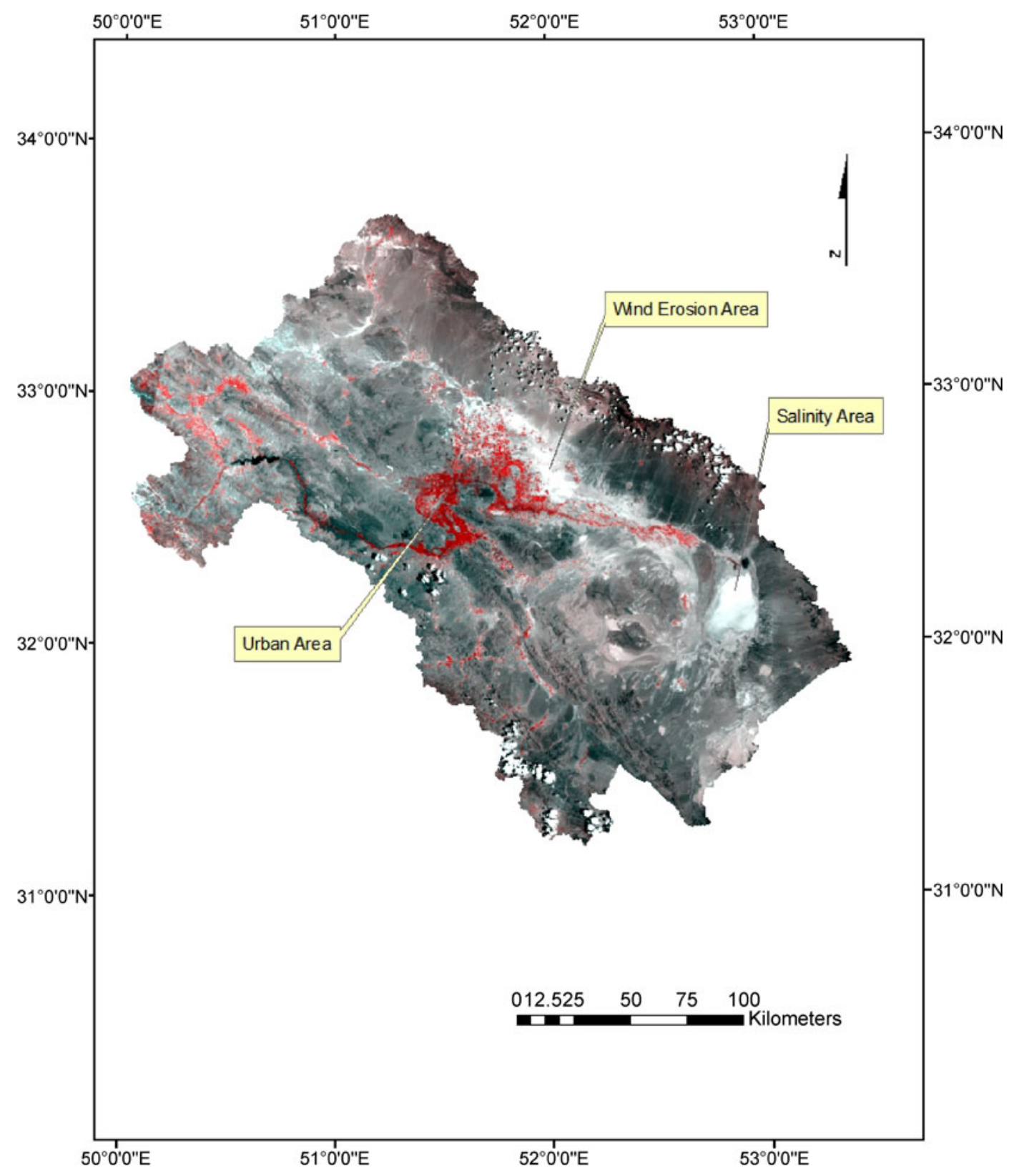

Figure 2. Location of Z.R.B by landsat images.

relationship between the bands and to identify the conduct of the spectral salinization area within the study area using composite colours of the spectral curves. On examination of the spectral curves, numerous composite bands such as $653,356,742$, 321, 432, 531 were studied. Among the real and false colour composites examined were 321,742 and 432 judged to be the best composite colour to recognize and identify the land cover of the study area.

Composite band productions: The images were clear and in contrast on examining the spectral curve and testing the different real and false composites such as $432,742,731,321$ by enhancing the conduct such as filtering and using the contrast line of the images. With this method, it is possible to identify land cover: salinization, vegetation, etc.

Mapping DEM (Digital Elevation Model): To develop the method, a topographical map with a 1:50,000 scale converted to digital data processed and a mosaic converted to vector using an internal method, a Digital Elevation Model was developed. The aim of the operation was only to display the scope of the study area with a composite of 432 bands over the DEM.

\subsubsection{Statistical data}

Climatic parameters such as temperature and precipitation were used for the climatic quality map. 


\subsection{Methodology}

Reclassification of the vector maps and rasters was made based on the purposes of the study. For each parameter, the information for overlap and classification was provided by spatial analysis in the GIS environment.

\subsubsection{GIS operation}

Classification of each vector map was based on scoring and mapping of the desertification hazard map in GIS environment. The following section will explain the maps for the classified vectors and raster for the classified desertification hazard map:

Soil: In desert area, soil loss plays an important role in increasing the desertification rate. Soil temperature, soil organic matter, soil slope and soil depth play their roles in desert ecosystems. In this study, the soil dataset was used for soil characteristics such as depth, texture and parent soil. The soil information was extracted by using a vector map. The soil depth and texture were classified in the GIS environment. Tables 1-4 show the classes of soil characteristics in this study. The soil information was collected by using the reviews of the studies of Natural Resources Organization of Iran.

Climate quality: Climatic factors such as wind, evaporation, precipitation and temperature are important factors for the development of deserts in arid and semi-arid areas. A climate quality map was classified on the annual precipitation and potential for evaporation by climatologic organizations (table 5).

Land use: One of the direct effect of factors responsible for desertification and land degradation is land use. Land use is a function of human activities. In Z.R.B, since the climate and topography are different, land use differs. In this study, land use classification was reclassified based on the purpose of study and by using LANDSAT images ETM+ (table 6).

Elevation: An important parameter for assessment and desertification is elevation. Due to difference in height in Z.R.B, elevation should count

Table 1. Classes for parent of soil.

\begin{tabular}{lll}
\hline Class & Description & Score \\
\hline Limestone-conglomerate & Good & 1 \\
New alluvial-lime stone & Moderate & 1.5 \\
Alluvial-salt chalk & Poor & 2 \\
\hline
\end{tabular}

Table 2. Classes for slope of soil.

\begin{tabular}{lll}
\hline Class & Description & Score \\
\hline Gentle & $0-3.18$ & 0.25 \\
Not very gentle & $3.18-8.87$ & 0.5 \\
Very gentle & $8.87-16.81$ & 0.75 \\
Abrupt & $16.81-26.96$ & 1 \\
Very abrupt & $29.56-67.05$ & 1.25 \\
\hline
\end{tabular}

Table 3. Classes for depth of soil.

\begin{tabular}{llc}
\hline Class & Description & Score \\
\hline Very shallow & $>0.25$ & 2 \\
Shallow & $0.25-0.50$ & 1.5 \\
Deep & $0.5-1$ & 1 \\
Very deep & $>1 \mathrm{~m}$ & 0.5 \\
\hline
\end{tabular}

Table 4. Classes for texture of soil.

\begin{tabular}{lll}
\hline Class & Description & Score \\
\hline Clay-high salinization & Low & 1 \\
Loamy & Moderate & 1.5 \\
Sandy & High & 2 \\
\hline
\end{tabular}

Table 5. Classes of climate quality.

\begin{tabular}{ll}
\hline Class & Score \\
\hline Hyper-arid & 1.5 \\
Arid & 1.25 \\
Semi-arid & 1 \\
Semi-humid & 0.75 \\
Humid & 0.5 \\
\hline
\end{tabular}

Table 6. Classes of land use for assessing desertification.

\begin{tabular}{llc}
\hline Class & \multicolumn{1}{c}{ Description } & Score \\
\hline Low & $\begin{array}{l}\text { Forest } \\
\text { Agriculture }\end{array}$ & 1 \\
& $\begin{array}{l}\text { Pasture land } \\
\text { Low pasture land }\end{array}$ & \\
Moderate & Water body & \\
& Urban \\
High & $\begin{array}{l}\text { Salty land } \\
\text { Bayer land } \\
\text { Sand dune }\end{array}$ & \\
& & \\
\hline
\end{tabular}

Table 7. Classes and estimate for elevation for assessing desertification.

\begin{tabular}{lll}
\hline Class & Description & Score \\
\hline $1554-2031.2$ & Very low & 2 \\
$2031.2-2508.4$ & Low & 1.75 \\
$2508.4-2985.6$ & Moderate & 1.5 \\
$2985.6-3462.8$ & High & 1 \\
$3462.8-3940$ & Very high & 0.5 \\
\hline
\end{tabular}


Table 8. Classes and estimate for wind and water erosion for assessing desertification.

\begin{tabular}{lll}
\hline Class & Description & Score \\
\hline Wind erosion & Low & 1 \\
& Moderate & 1.5 \\
& High & 2 \\
Water erosion & & \\
Surface erosion (low) & Very low & 2 \\
Surface erosion (low-moderate) & Low & 1.75 \\
Surface erosion-gully (moderate) & Moderate & 1.5 \\
Gully erosion & High & 1.25 \\
Surface erosion-stream & Very high & 1 \\
\hline
\end{tabular}

as a parameter for the desertification hazard map. DEM was used for calculating the elevation of the study area (table 7).

Erosion: Wind erosion and water erosion are two measurable factors for desertification classification. Wind erosion was measured using IRFR method in three classes. Water erosion was classified based on the types of parameters: surface erosion, gully, and stream erosion (Consultant Engineering 2007), (table 8).

In this study, parameters were classified based on the preview models. The sum of the factors serves as an indicator for level classification. Geomorphologic faces were used as a base map for scoring. The scores were calculated and then using a

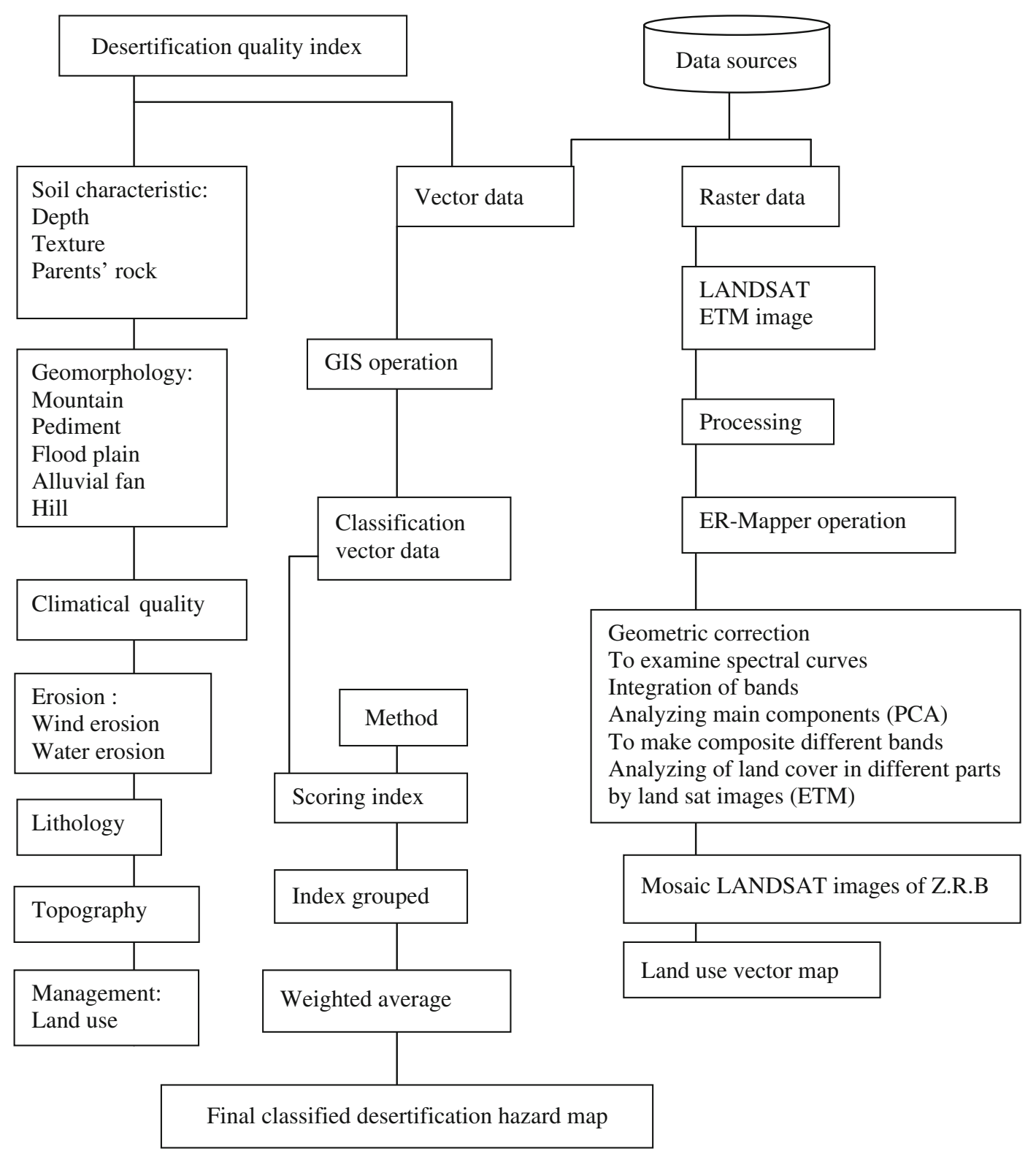

Figure 3. Flowchart of mapping classification desertification map. 

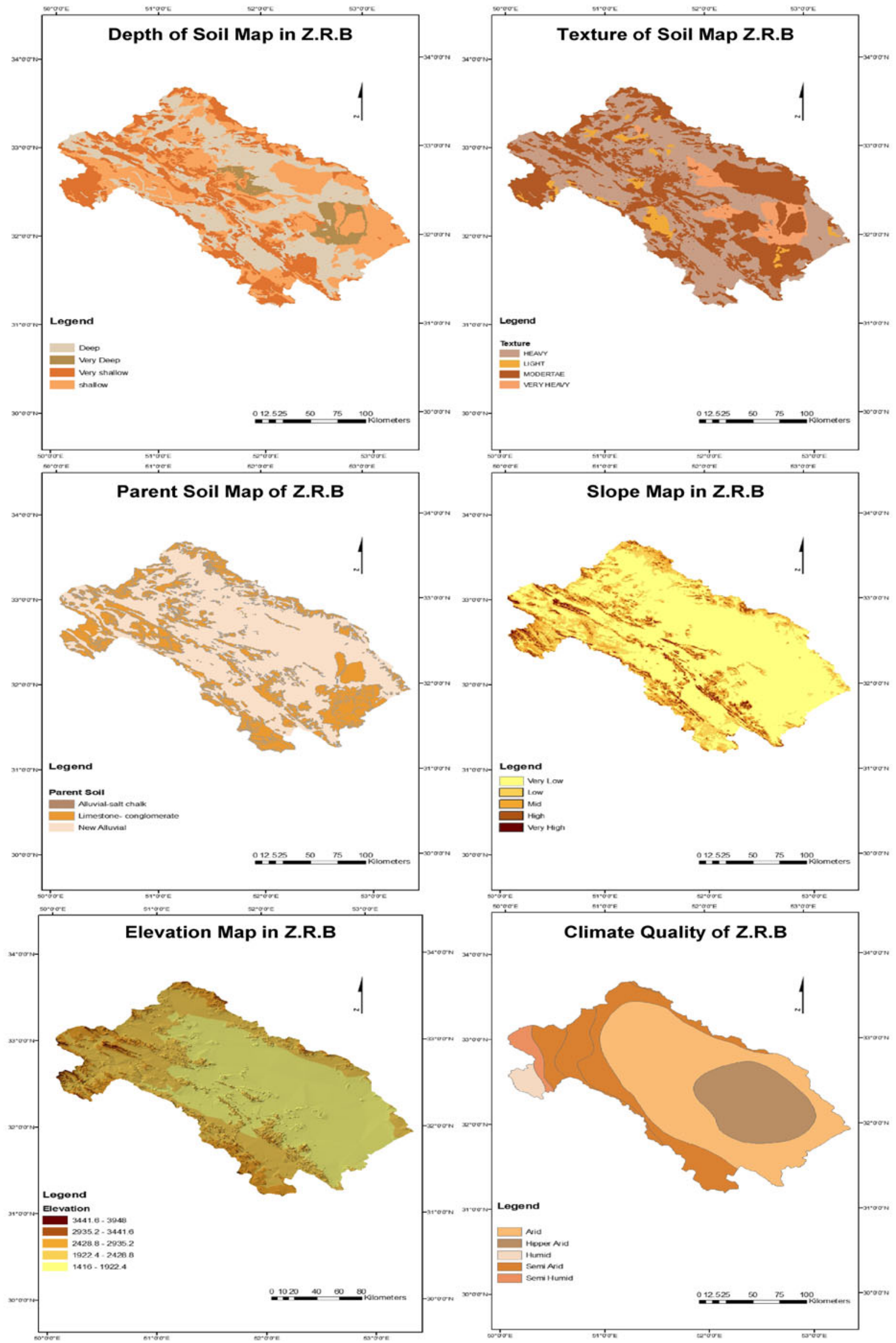

Figure 4. Classified characteristic of soil parameters map. 
weighted average, all the factors were calculated. The weighted average of the figures obtained from the factors within each geomorphologic section as well as the classified parameters used for weighing were evaluated in a polygon-attribute table and displayed as classification hazard maps (figures 3 and 4).

The final stage of the method was to use LANDSAT images (ETM+, 2002) to check the area. By selecting different bands and then overlapping them with the classification map, five classes of the classification map were checked.

\section{Discussion and results}

\subsection{Interpretation of LANDSAT ETM+ images of the study area}

Satellite images should be used to monitor the land use, salinity and degradation of areas.
Satellite ETM images of land were used for visual interpretation of salinity and desert areas identified as bright white on the images. The LANDSAT images ETM+ 2002 highlighted the salinity and vegetation areas. Digital analysis of the satellite data of LANDSAT images ETM+ yielded sets of digital maps. The analysis of the satellite data revealed an area under the influence of human activities, geomorphologic land form and showing poor agriculture in degraded and salinity areas.

\subsection{Classification desertification hazard map analysis}

Depending on the situation of the area, desertification factors can be recognized. The factors can be geographical situation, geomorphologic faces, climatic and managerial function. With regard to Z.R.B, the most important factors are geographical location, climatic quality, management, soil

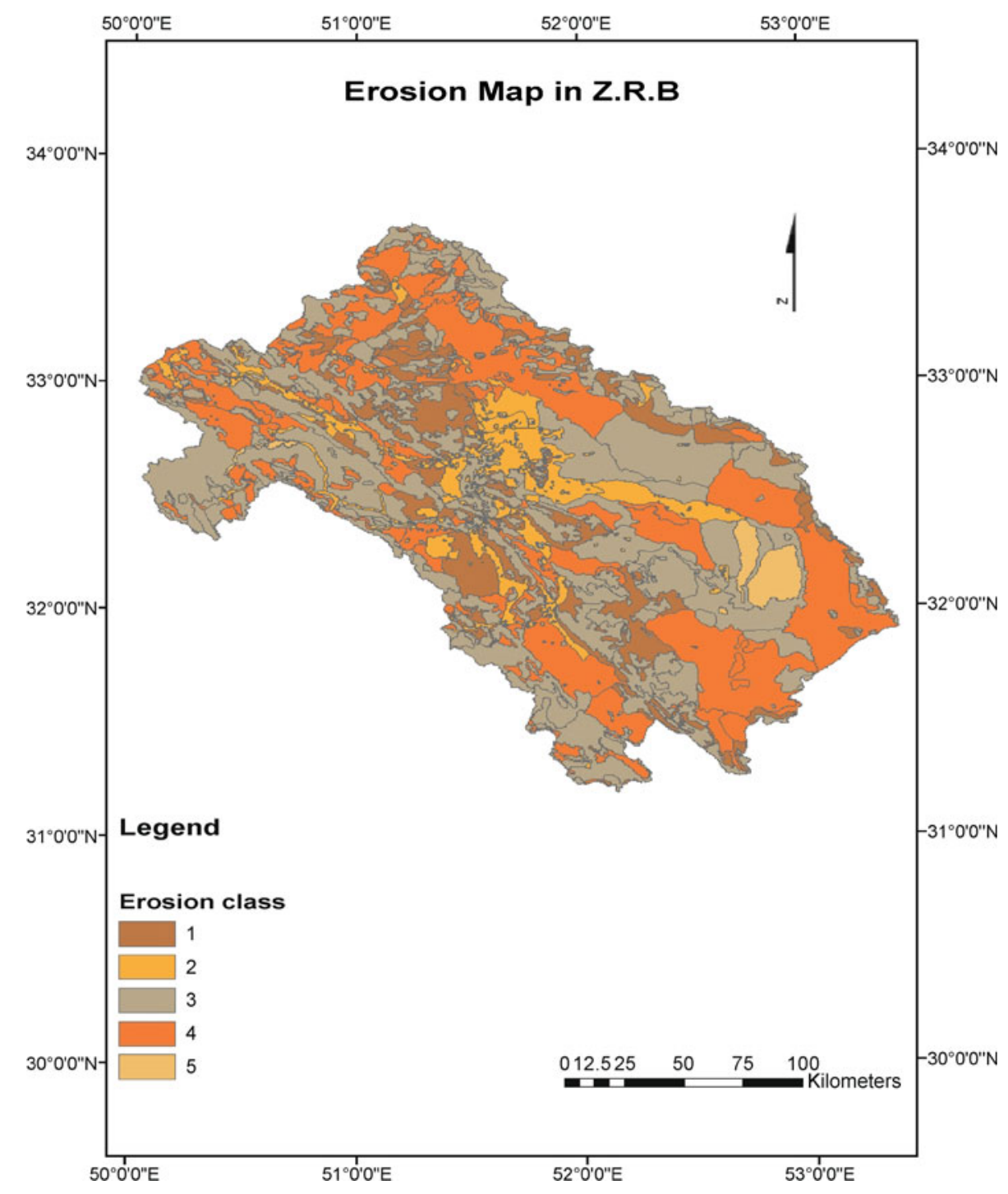

Figure 5. Classified erosion in Z.R.B. 
characteristics and topography. To combine and calculate the method for measurable parameters, a weighted average was used in this study. Classification of each parameter such as soil dataset, climate, land use, erosion and elevation were the results of a desertification assessment (figure 4). The study area was a hydrology basin of about $42,000 \mathrm{~km}$ with a variety of climates, landforms, geographical locations, soil and lithology.

\subsubsection{Soil characteristics of Z.R.B.}

The soil parent of the study area included granite, gneiss, limestone, dolomite, shale, and sandstone. On the east of Z.R.B, sandstones, dolomite and lime extend non-uniformly among the sedimentary stones (lime, shale and marl). In the Z.R.B, there are new sediments such as gravel produced by the draught of lakes in the basin, largely in the northern and eastern plains of the basin. Further, there are evaporating sediments containing salt and chalk around the Govkhooni Marsh (Consultant Engineering 1997a).

In the mountainous area of Z.R.B, $70 \%$ of the area is composed of lime stones, conglomerate and marl limes. The slope of this type varies from 25 to over $40 \%$ at different points with low deep soil of light-to-moderate texture. In $12-25 \%$ slope hills, there are igneous, metamorphic, chalk marl and sandstones of light-to-moderate texture and low slope. $2-8 \%$ of the total basin is side slopes with deep to half deep gravel of light-to-moderate texture. The low and high chalk and marl are in the slope 5-8\% gradient with a heavy deep texture. In the $1 \%$ slope gradient, deep soil of average-to-heavy texture contain high salinity, alkaline, chalk and salt crystals. The eastern part of the Z.R.B is too deep of heavy and too heavy

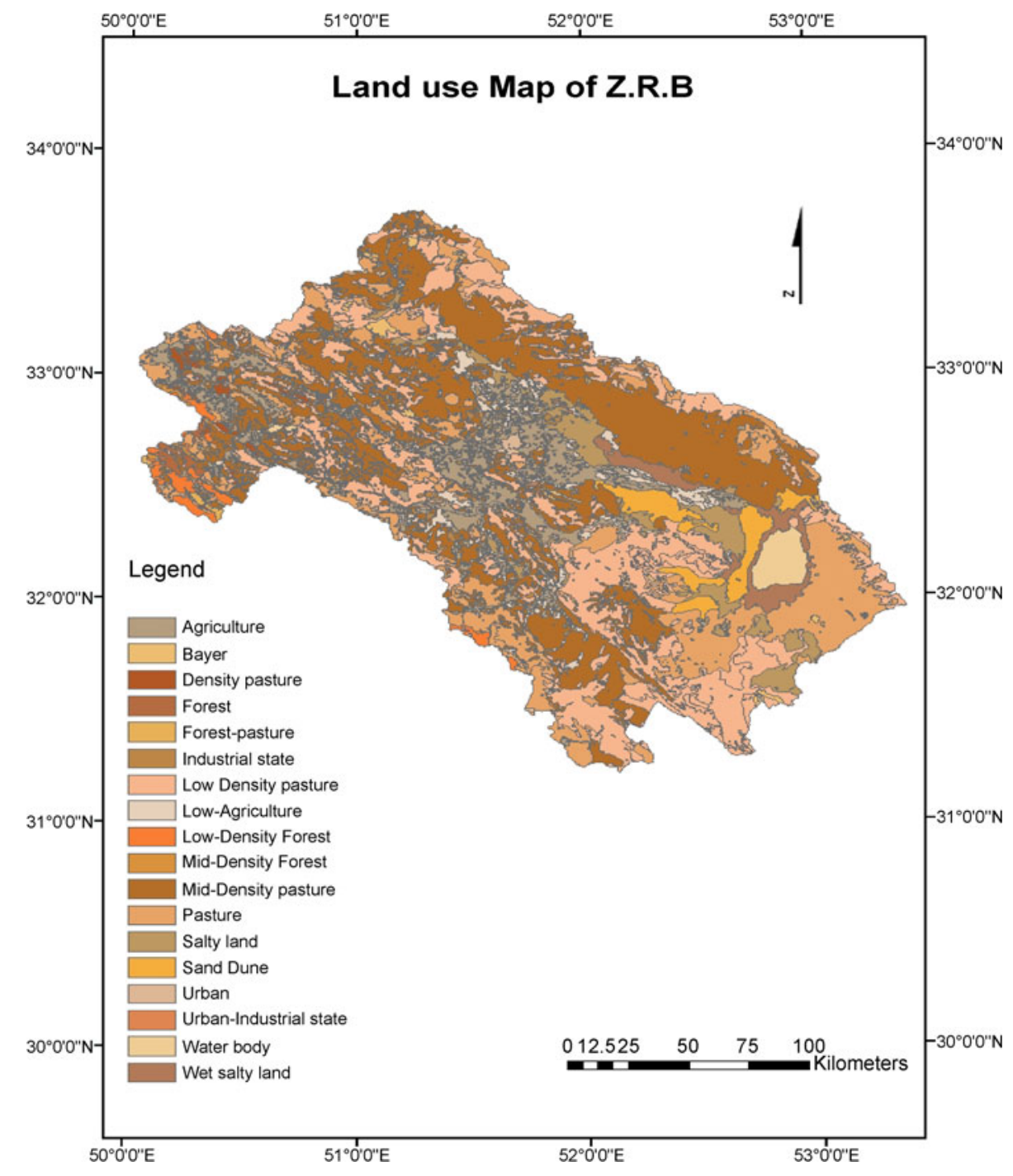

Figure 6. Classified land use in Z.R.B. 
texture whose surface contains mining materials (figure 4).

\subsubsection{Elevation}

The highest part of the basin is located in the west and southwestern regions. The lowest part is located at east of the basin. As can be seen, about $60 \%$ of the basin is lower than $2000 \mathrm{~m}$ and $33 \%$ is between 2000 to $2500 \mathrm{~m}$ and only $7.2 \%$ is higher than $2500 \mathrm{~m}$ (figure 4). The average height of the basin weight is about $1957 \mathrm{~m}$ (Khodagholi 2006) such that the lowest part of the basin, namely the eastern part, is about $800 \mathrm{~m}$ (the high and highest class of desertification area) (figure 4).

\subsubsection{Climate quality}

In the Z.R.B, the main effective component is the height of the area which reduces the air temperature and pressure as well as the precipitations. However, because of the rainfall originating from the massifs in the west, there are more precipitations compared to that in the eastern part of the basin with low elevations (Khodagholi 2006). The largest part of the basin (eastern part) has a greater temperature and evaporation, lower precipitation and higher wind speeds (figure 4). Moderate, high to highest rate of desertification occurs in the Z.R.B region (figure 4).

\subsubsection{Erosion}

Wind erosion is an important factor for the existing desertification. The northern and eastern parts of the Z.R.B typically reflect the highest rate of wind erosion. The appearance of the area was covered by sandy and chalky faces due to wind erosion.

Owing to high rainfall and lack of vegetation, water erosion occurs west and north of the Z.R.B

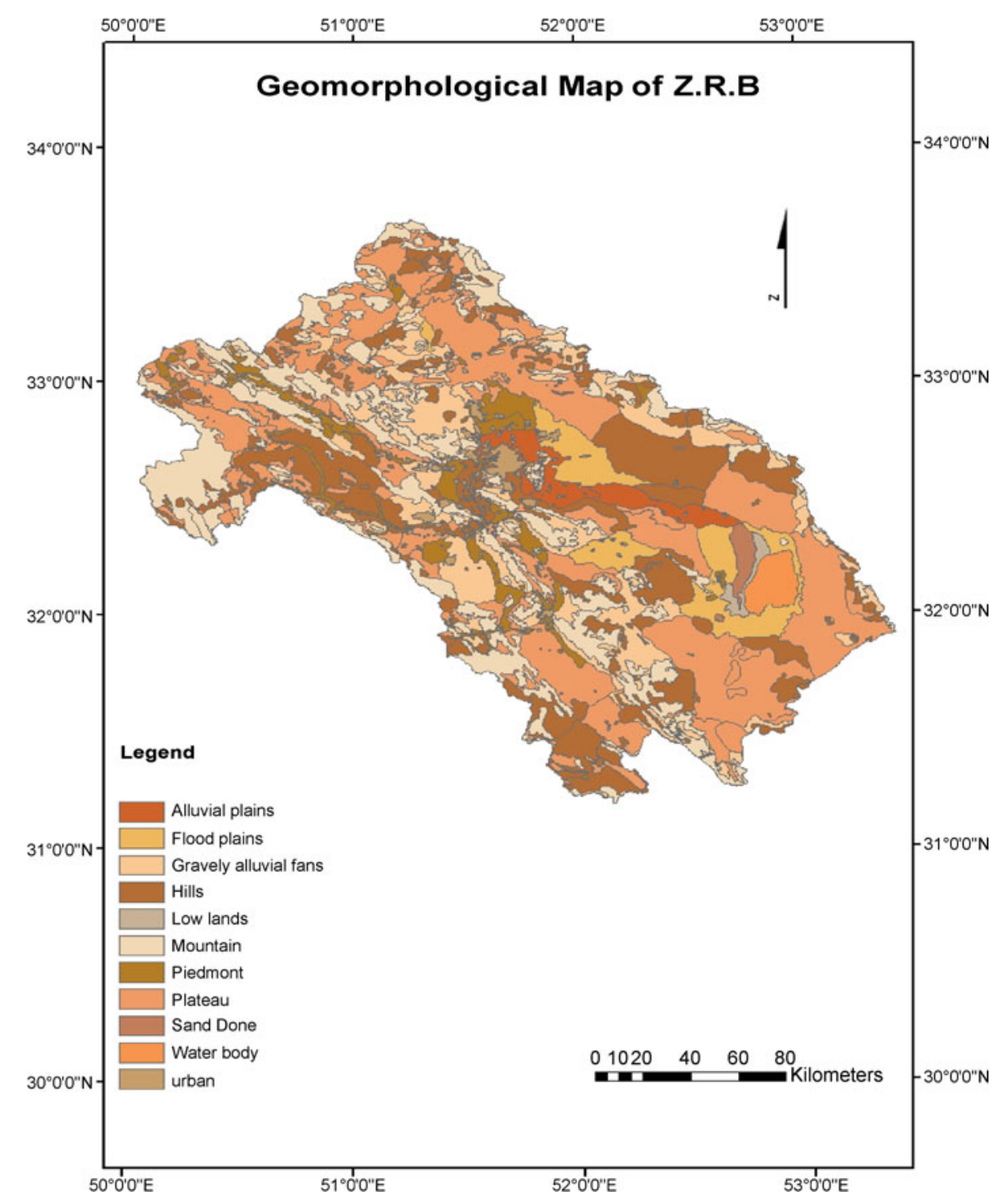

Figure 7. Classified geomorphological in Z.R.B. 
(mountain area) within the Z.R.B. Types of water erosion include surface erosion, stream erosion and gully erosion (figure 5).

\subsubsection{Land use}

In general, pastures and uncultivated lands are the dominant land use in the study area. The central part of the Z.R.B area is agricultural. Bayer land is located in east, north and central east of the Z.R.B. The eastern and northern parts of the basin have a greater potential for developing deserts. The third and fourth classes of desertification hazard map are located on the pasture and barren land area (figure 6). Most of the forests and rain-fed areas are also located west and northwest of the Z.R.B.

\subsubsection{Geomorphologic units}

Mountains and high elevations extending to the western part of the Z.R.B and playas are located on central and eastern parts of the Z.R.B. The numerous alluvial plains are located on the outskirts of the mountainous area in the Z.R.B. There are associated terrace, different playas, different alluvial fan and seasonal stream alluviums in the Z.R.B. There are playas and plains composed of the Zayandeh Rood River sediment, alkalinity, largely of ground water and $0.5 \%$ slope, often with grass and prairie. Water body such as Govkhooni Marsh, a playa is located in the eastern part of the Z.R.B (figure 7). Gavkhooni playa is one of the sediment playas which serves as a tectonic seduction between the folds filled with the sediment from the

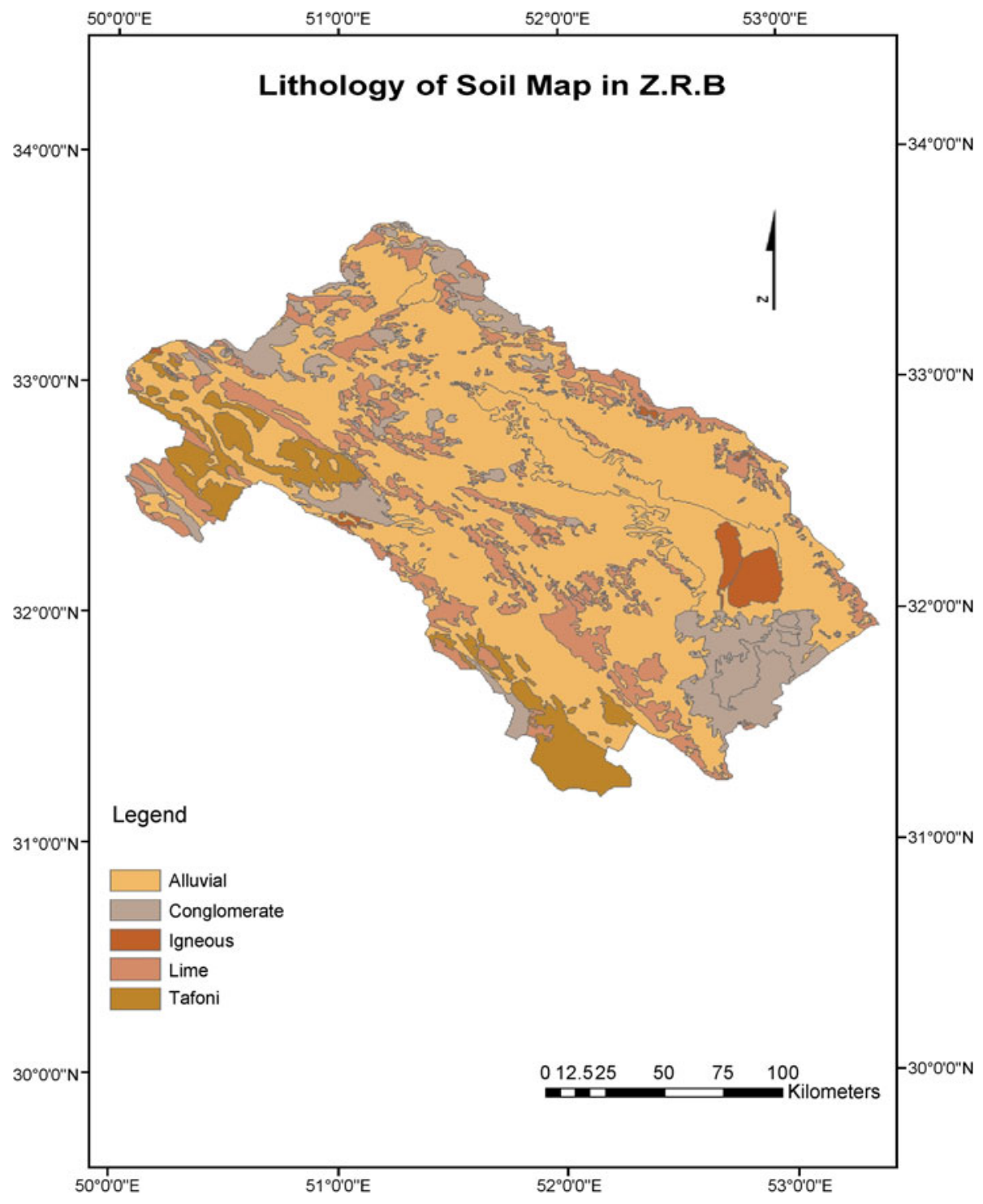

Figure 8. Classified lithology in Z.R.B. 


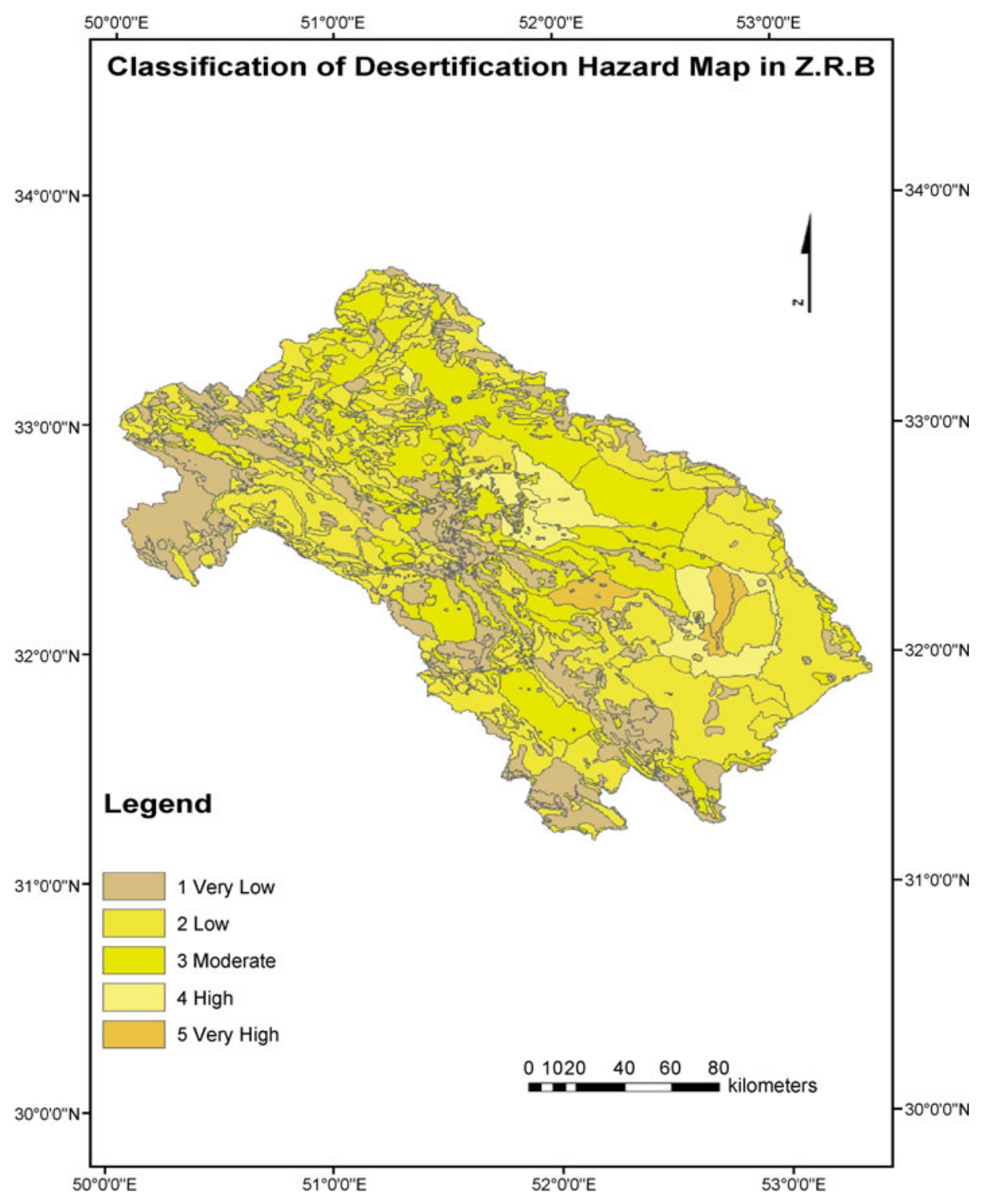

Figure 9. Classification hazard map of Z.R.B for assessing desertification.

Table 9. Classified desertification area in Z.R.B.

\begin{tabular}{lclcc}
\hline Classes & Score & \multicolumn{1}{c}{ Description } & Area $\left(\mathrm{km}^{2}\right)$ & Area $(\%)$ \\
\hline 1 & 1 & Very low sensitive & 9277.12 & 22.36 \\
2 & 2 & Low sensitive & 17039.99 & 41.07 \\
3 & 3 & Moderate sensitive area & 11880.05 & 28.63 \\
4 & 4 & High sensitive & 2474.21 & 5.96 \\
5 & 5 & Very high sensitive & 816.02 & 1.96 \\
Total & & & 41487.4 & 100 \\
\hline
\end{tabular}

surrounding mountains. Based on the sedimento logical and palaeoclimatological evidences, it appears that the Gavkhuni Marsh was larger during the late Tertiary period (Jafarian 1986; Toomanian et al. 2006).

\subsubsection{Lithology}

In the study area, granite, gneiss, schist and andesite stone massifs belong to the Precambrian period, the oldest formation. Stones of Triassic 
period can be divided into two parts. The lower part is composed of lime and dolomite stones, new and old alluvial and the upper part is generated from tafoni, shale and sandstone. In the eastern part of the basin, there is shale and in the western part of the basin, there is Jurassic formation. In its upper part, there are lime stones and in the lower part, there are lime and shale. In the eastern part of the study area, there are sandstones, dolomite and lime extending from the Carboniferous period. Non-conformity among the sedimentary stones (lime, shale and marl), Barmin-Apsin and different Jurassic stones and Triassic shows the advancement of the cretaceous sea in the region. The faces from the cretaceous period are largely found at the basin level extending more towards the southern part (figure 8), (Consultant Engineering 1997b).

In the Z.R.B, the pediment type is a slope plain of 153,659 hectares area which is a land unit slope plain with much salinity and alkalinity, puffing surface and less than 1\% slope, deep soil of averageto-heavy texture, with much of salinity and alkalinity of chalk and salt crystals. These land units are found in the northern Z.R.B. In the area, there are alluvial fan and slope alluvial plain type.

\subsection{Composite layers and classified desertification map}

The hazard classification map shows five classes of desertification in the Z.R.B (figure 9). Classified hazard map was driven by composite of layers which are soil, climate quality, elevation, land use and erosion in form of five classes. A very high class for desertification in the study area is $1.96 \%$ of the total study area. The location of the classes is the lowest slope gradient, elevation and hyperarid area in the eastern part of the Z.R.B. High sensitive area is $5.96 \%$ of the total study area of $2474.21 \mathrm{~km}^{2}$. The moderate represents $28.63 \%$ of the total study area of $11,880.05 \mathrm{~km}^{2}$. Low classes included a large area of the basin. It is 41.07 of the total area of $17,039.99 \mathrm{~km}^{2}$. A lowest class includes $22.36 \%$ of $9277.12 \mathrm{~km}^{2}$. The location of the area is a high elevation, slope gradient (table 9 ).

\section{Conclusions}

This study evaluated a classification hazard map. The methodology was developed by studying the desertification factors and geomorphologic faces. The hazard classification map provides conditions for recognizing the critical centers of hazards and prevents the hazards in the basin. In the regions, the lime materials of soil increases due to weathering of the lime formation such that some layers with limited lime are made which are not suitable for the growth of plants. As a result, natural vegetation decreases and soil erosion occurs. Desertification factors such as climate, topography, land use, geographical situation are effective in the development of desertification. The development of technology has influenced the quantitative assessment of desertification using remote-sensing and GIS software as valuable techniques for a classification hazard map, especially for large areas. A large part of the area is located in the arid and semi-arid areas, slopes, elevations and climates seem to be the major factor in the development of desertification.

\section{Acknowledgements}

This work was supported by the University of Malaya and the data gathered was supported by the Natural Resources Organization of Isfahan, Iran and Sepahan Andish Consulting Engineering for the Hazard Information Data (2007).

\section{References}

Afif A G et al. 2010 Use of GIS and remote sensing for environmental sensitivity assessment of north coastal part, Egypt; J. Am. Sci. 6(11) 632-646.

Ahmadi H, Abrisham E, Ekhtesasi M R et al. 2006 Assessment and mapping of desertification using MICD and ICD model in FakhrAbad, Mehriz region; Desert J. 10(1) 165-187.

Alavipanah S K and Zehtabian G R 2001 Remote sensing and GIS tools for planning and management; Nat. Resour. J. Iran 601.

Aminmansour M 2006 Drought and desertification in Iran; http://www.parstimes.com/environment/desertification_ iran.html.

Consultant Engineering 1997a Surface water resources reports in Govkhooni Marsh, Yazd and Ardestan area.

Consultant Engineering 1997b Zayandeh Rood Basin and Govkhooni Marsh reports; Natural Resources Organization of Isfahan.

Consultant Engineering 2007 The plan of executive critical center of wind erosion in Sejzy Desert in Isfahan; Natural Resources Organization of Isfahan.

Dwivedi R S and Sreenivas K 1998 Delineation of saltaffected soils and waterlogged areas in the Indo-Gangetic plains using IRS-1C LISS-III data; Int. J. Remote Sens. 19(14) 2739-2751.

Ekhtesasi M R and Mohajeri S 1995 Method of classification for type and intensity of desertification in Iran erosion sedimentation potential with use of IRIFR. E. A and MPSIAK Models in Semi-Arid; http://www.fig.net/ pub/proceedings/korea/full-papers/session28/alavipanahzehtabian.htm.

Gosh T K 1993 Environmental impact analysis of desertification through remote sensing and land based information system; J. Arid Environ. 25 141-150. 
Graetz R D, Pech R P and Davis A W 1988 The assessment and monitoring of sparsely vegetated rangelands using calibrated LANDSAT data; Int. J. Remote Sens. 9 1201-1222.

Greek National Committee for Combating Desertification 2001 Greek national action plan for combating desertification; Athens.

Gurung J D 2010 Gender and desertification; International Fund for Agricultural Development; Via Paolo di Dono 44 00142, Rome, Italy.

Hansen D B 1985 An evaluation of FWS and BLM geographic data processing capabilities; Proceedings, Annual Meeting of the American Society of Photogrammetry, Falls Church, Virginia; The America Society of Photogrammetery, pp. 712-727.

Jafarian M A 1986 Study of paleogeopraphy and evolution stages in Zayandeh Rood Valley; Research Publication of Isfahan University, Spring, 15p (in Persian).
Jing-hu P A N and Tian-yu L I 2010 Extracting desertification from LANDSAT imagery based on spectral mixture analysis and Albedo-Vegetation feature space; J. Natural Resourc. 25(11) 1960-1969.

Khodagholi M 2006 A survey of phyto-climatology of Zayandehroud basin; Pajouhesh Sazandegi 70 41-53.

Ladisa G, Todorovic M and Trisorio Liuzzi G 2002 Environmental sensitive areas to desertification model: Supplementary indicators accounting for particular environmental conditions of southern Italy; Proceedings of International Conference on Environmental Problems of the Mediterranean Region, Near East University, Nicosia, North Cyprus.

Sepehr A 2007 Quantitative assessment of desertification in south of Iran using MEDALUS method; Environ. Monit. Assess. 134 243-254.

Toomanian N et al. 2006 Pedodiversity and pedogenesis in Zayandeh-rud Valley; Central Iran Geomorphology $\mathbf{8 1}$ 376-393. 